\title{
Aligning Collections Budget with Program Priorities: A Modified Zero-Based Approach
}

\section{Gayle R. Y. C. Chan}

Gayle R. Y. C. Chan, University of Hong Kong Libraries, Pokfulam Road, Hong Kong

E-mail address: gryclibr@hkucc.hku.hk

\begin{abstract}
The paper discusses the impact of zero-based budgeting on the budget allocation process at the University of Hong Kong Libraries (HKUL). The challenges and strategies to optimize the collections budget in reallocating resources from print to electronic publication within an environment of inflationary increases and reduced funding increases are addressed. An examination into HKUL's past and current practices compares and contrasts the use of different budget allocation methodologies. A recent modified zero-based budget review has provided opportunities for faculty participation with the result of an effective approach in aligning collections budget with changing program needs.
\end{abstract}

Keywords: collection development; collection assessment; library materials budget; budget allocation; zero-based budgeting; 


\section{Introduction}

Program needs assessment is always the foremost feature of the library materials budget allocation process. At the University of Hong Kong Libraries (HKUL), the broad strategy to align collections with budget allocation is to address high priority and new program needs in developing areas indicated by collection assessment data. The Libraries subject policies and new program impact statements are regularly updated to reflect the latest academic developments and describe the current state of collection, highlighting the collection strengths and weaknesses of the HKUL's collections. Such policies and statements are used as a collection development tool to plan the way forward for the changing needs in the University's teaching and research. Other budget considerations include the balance between expenditures in different formats purchased, materials pricing changes, publishing output in each subject discipline, usage of collection for good return on investment, and user preference. For the past five fiscal years, HKUL has annually tried to establish faculty's real needs in terms of their expenditure pattern to project future budget needs. Recently, broad zero-based budgeting principles are also applied in the analysis to better align collections budget with changing program needs arising from a changing institutional environment.

In recent years, budget allocation decisions have become far more complex and difficult, partially due to the swift reallocation of the collections budget from print to electronic publications. The continued emphasis placed on electronic resources, coupled with the lack of growth in library budgets to sustain collection growth have exacerbated the need to reprioritize program needs and to redirect funds from lower priority use to higher priority use in the allocation of the materials budget. New information resources are released every year with substantial price increase. The question arises as to how a library supports increased spending to build robust collections to meet new program needs when there are insufficient funds to keep up with annual rising costs 
averaging up to $8 \%$. How to make adjustments to support increased spending on digital collections to expand access to resources? What principles to rely on in order to ensure sound allocation decisions, and what are the strategies behind those decisions? These are just some of the questions that need to be addressed in formulating the allocation of the collections budget.

The purpose of this study is to examine the application of zero-based budgeting (ZBB) principles in the context of the library environment, and to discuss the pros and cons of the methodology. The paper puts into perspectives the allocation processes involved in implementing modified zero-based budgeting, including the preparation and submission of a budget request, and the allocation decisions taken to derive the overall Library Resources Fund (LRF). The resulting impact and the effectiveness in aligning collection goals are evaluated based on the outcomes of the budget allocations. The findings from this study are expected to help guide future directions in exploring further options to improve the current materials budget allocation model.

\subsection{The University environment}

The University of Hong Kong (HKU) is an English-medium university that offers a wide range of programs leading to undergraduate and postgraduate qualifications through its ten faculties, six of which are the professional schools of Medicine, Dentistry, Architecture, Education, Engineering and Law. Postgraduate students currently account for 38\% of its current student population of 16,673. In addition, it has a strong continuing education arm which offers extensive programs in more than 40 subject areas, including full-time associate degree and higher diploma programs in its Community College. The University of Hong Kong has climbed up to $18^{\text {th }}$ place in 2007 from $33^{\text {rd }}$ in 2006 in the Times Higher World University world ranking, and strives to sustain its standing as a world class, research-led, international university. HKU is approaching its centenary in 2011, and is in the process of implementing plans for its new 
Centennial Campus, which will almost double the size of the existing main campus and be equipped with leading edge teaching and research facilities .

With this expansion, the Libraries will have to accommodate an anticipated forty percent increase in student numbers partly due to the new four-year university curriculum which begins in 2012, and additionally, 200 faculty positions created to enhance research competitiveness in the delivery of the four year curriculum. One of the major challenges for the Libraries in recent years is to address the diverse learning communities that adopt multiple instructional strategies, technology based formats, experiential learning in a digital learning and research environment. The Libraries addresses this challenge by moving towards a system that places emphasis in providing access to its full range of latest information and communication technologies and digital collections, such as, multi-media content, digitized unique local content and advanced discovery tools that permit federated search functions across multiple holdings catalogs.

The function of collection development at HKUL is characterized by close consultation with faculty members and students, and hence remains user-centered and is directed at user needs. Topical collection assessment projects are undertaken only in consultation with the faculty to ensure alignment of the collections for new programs and emerging areas. The rationale of the budget allocations to shift from print to electronic format is clearly communicated to members of the Faculty Library Committees and stakeholders, and it is clearly understood that site-license fees increases for new electronic contents will make it necessary to further reduce print serials expenditures. Since 2002, the Libraries merged all the departmental/faculty funds spent on electronic resources to a central Shared Electronic Resources Fund for better monitoring of electronic resources expenditures in all subjects and disciplines. An advisory committee has been set up to provide additional guidance to the Collection Development Team and Libraries Administration in the expenditure of the Fund. The purpose is to ensure that the development of 
the Libraries' Digital Collections reflects the priorities and needs of the University community.

Subsequent to an audit review by the university's Internal Audit Office in February 2006, the University of Hong Kong Libraries (HKUL) implemented zero-based budgeting (ZBB) principles in the allocation of its library materials budget in response to the recommendation made by the Internal Audit Committee. In the initial phase, the Libraries undertook a modified ZBB review by examining the needs of each faculty in terms of the following factors: 1) new program/ research needs, 2) materials cost increase, 3) usage, 4) peer benchmarking, 5) expenditure pattern, and 6) inadequacies and other factors deemed important. Although the mentioned criteria are not new and have always been considered in previous budget allocations, the ZBB exercise requires that each faculty submits a funding request to justify their "future" funding needs.

The focus of the paper will discuss how modified zero-based budgeting (MZBB) has impacted the budget allocation processes and decisions at the University of Hong Kong Libraries, and examines the strategies to optimize collections budget within an environment of inflationary costs. An examination into HKUL's past and current practices provides a means to compare and contrast the use of different budget allocation methodologies.

\section{Budget Allocation Process: Past and Current Practices}

\subsection{From formula-based allocation to allocation based on needs}

The HKU Library Resource Fund (LRF) allocation was traditionally formula-based up until 1998. Average materials pricing in the different disciplines and population size of faculty and students were major elements factored in, although these numbers were not linked to actual teaching and research activities. The major drawback was that the formula only applied to the increment portion of the annual budget, hence the adjustment was limited and never fully reflected 
the factors mentioned. When the budget increase began to flatten with reduced increment from mid 1990's reaching negative growth in early 2000, the formula was deemed invalid and its subsequent use was reviewed. The protection of no-growth scenario was not built into the formula. The formula was also deemed too inflexible to accommodate the changing curricula and research needs of new programs or areas of research focus. Furthermore, the formula did not address the adjustments needed to shift from print to electronic-only options.

The formula was traditionally adopted to minimize competition in times of budget constraints and to achieve higher degree of equity and objectivity. Although it was possible to improve the formula by incorporating other activities-driven variables with the appropriate performance measures, as mentioned in the library literature (Clark, McCaslin and George, 2005; Sudarsan, 2006; Weston, 2004), such as, the extent of library use, instruction in terms of credit hours, program level, research funding and publication index, the weakness of the formula based allocation was generally realized by the senior library management team. In short, the formula based allocation did not cater for actual needs, new program, research needs and particularly interdisciplinary needs. Moreover, the formula did not factor in the shift of funds needed for the development of electronic resources. With an almost flat budget (zero increase), the historic base simply could not be continually justified with faculties expecting some percent of increase to absorb inflationary increases. Since no perfect formula exists that could take into account all variables because competing needs are so diverse, the management decided to give up the formula for a more flexible approach that would better reflect future program needs, pricing and the shift towards increased emphasis on electronic resources.

The model of allocation process adopted since abandoning the formula was primarily based on factors deemed pertinent to reflect changing circumstances and would optimize fiscal flexibility in times of budget constraints. The factors examined when allocating the library 
materials budget included the consideration in the balance between expenditures on different formats, the expenditure pattern, materials pricing and publication output.

The overall balance between print and electronic expenditures was of primary concern as the Libraries began to place more emphasis on electronic resources to build its digital collections. The proportion or percentage of print monographs, print serials and electronic resources was carefully balance to ensure that each format is sufficiently funded. The growth in electronic resources was accommodated with an annual increase in the electronic resources budget without eroding the print budgets for monograph dependent disciplines. The net savings realized from the serials rationalization exercise, which is conducted annually to update collection priorities helped to achieve this balance between expenditures on the different formats purchased.

The annual expenditure pattern was used to establish each faculty's real needs. The expenditures were perceived to reflect to a large extent the actual information needs acquired to support teaching and learning. Discrepancies between collection goals and the acquisitions funding commitment resulting in collection weaknesses were addressed through adjustments in the coming year's budget allocation pending on funding availability. Under-utilized funds were exceptional and reviewed by the collection development head and subject librarians responsible to ensure that the information needs and collection goal level had indeed been met. Some of the reasons for under-spending were due to limited publications in the given subject discipline and stricter collection policy guidelines to discourage purchase of duplicate copies.

The budget process usually began with a review to look at price change data for monographs, print serials and electronic resources subscriptions to come up with realistic cost projections for the recurring portion of the budget, followed by sub-allocation of the remaining monographic portions to faculties. During times of budget constraints when most budget expenditures were 
fully expended, there was seldom additional budget increase or funds to be distributed among the faculties monograph funds, hence, faculties' base budget allocation adjustments were very minor and limited. When the electronic resources expenditures have grown at a much faster pace with double-digit growth averaging 25\% annually in the past five years compared with an average annual growth of $2.3 \%$ in the total library materials budgets, there was very limited funds to be re-distributed for new program needs. Significant or special funding needs for any new or developing programs simply could not be met without significant increase in the annual library materials budget, but only be considered using one-time supplemental funds.

\subsection{Adopting modified zero-based budgeting within the library context}

Recognizing the fiscal constraint to free up funds to support changing needs in the scenario described above, the university’s Internal Audit Office recommended that the Libraries undertake a zero-based budget (ZBB) review of its LRF allocation following an audit review. In times of limited budget increase or reduction, it was easy to understand why a system primarily based on expenditures pattern to project future needs would not be able to address funding needs arising from changes in academic direction. It was envisaged that such a review would help in readjusting the base allocations to support future budget needs in response to changing circumstances and developments even in times of zero budget increase. With the goal to better align expenditures against the goals and objectives of the University and the faculties' academic development plan, the Libraries welcomed the opportunity to apply ZBB principles to re-examine its allocation model to better align the budget with collections priorities. To adopt the principles behind zero-base budgeting to manage the allocations of their library budget, librarians consulted case studies of successful application in academic libraries (Linn, 2007; Foskett, 1991; Sargent 1978; Crowe, 1982; Hayton 1980). 
funding requests with the aim to eliminate or shift funding from low priority needs to high priority needs (Crowe, 1982; Sargeant, 1978). The ZBB process involves a cost and benefit analysis that aims to align closer the budget with program needs and objectives. It is a technique of planning and decision-making that emerged in the late 70's that requires managers to justify not only increases over previous year, but to entirely review objectives and function by defining costs and benefits and the most efficient ways to achieve (Austin and Cheek, 1979). Such a review forces reprioritization of "decision packages," or competing programs ranked in terms of its goals and objectives, measurement of performance, costs, benefits, and options (Austin and Cheek, 1979). Preparation of the budget typically involves steps to identify all activities and program changes; to analyze all associated costs to achieve objectives; to justify by examining alternatives and consequences of not funding; and to rank activities and/or programs in priority to decide upon allocations. This methodology is considered particularly useful in capital budgeting and multi-function activities for which there are competing but discretionary needs (CIPFA).

Initially, there was some apprehension and concern that such a review would take too much time and effort to collect data and to seek input from all stakeholders to justify every dollar from zero to come up with the budget. Normally, a full ZBB review would entail cutting each fund to zero dollars and to justify ongoing and new needs. Not being accountants, the Libraries adopted a pragmatic approach to begin with a modified zero base budget (MZBB) review instead of a full zero base review. In the initial phase, a base component of $95 \%$ of the previous year allocation was used to protect existing core needs and to lessen budget impact on weaker departments. Then on the basis of a review of the factors agreed upon, faculties were asked to propose additional budget needs for the library to decide how to reallocate the remaining $5 \%$ of the budget plus an additional sum of new money of 3.5\% of the total budgeted funds in 2007/08. Needs of each faculty were examined in terms of the following factors: 1 . new program/ research needs, 2. cost increase, 3. collection usage, $\quad 4$. collection assessment, $\quad$ 5. inadequacies and other 
factors deemed important.

A letter was sent to the Dean of each of the ten faculties to request a formal budget submission based on the variables mentioned. The budget request should state the additional funds needed beyond the base budget for information resources to support new identifiable needs in the different areas, which included teaching, research activities, new emerging areas/programs, increasing student numbers at different levels, specific new resources needed for specific new programs, and identifiable gaps in existing collections. Justifications could be price change related reasons, non price change related reasons, changes due to movement between budgets within the same funding area, and any other considerations deemed relevant.

For the cost and benefit analysis, the Collection Development Unit prepared data on collection usage, new programs implemented in the current year and ones planned for implementation, average book and serials pricing data for all the subject disciplines, recent collection assessment data including new program impact statements, and information on publishing trends for electronic resources, as well as the current expenditure pattern to note acquisitions level of each fund. An LRF Budget Review Subcommittee made up of Collection Development Team Members was formed to review budget submissions from the ten faculties and the Shared Electronic Resources Fund Advisory Committee.

In practice the Libraries materials budget is divided into three parts—-the recurring shared electronic resources fund which cover expenditures for electronic journals, the recurring print serials funds, and the one-time monograph funds. The first crucial step was to readjust the base of these three funds at $95 \%$ of the previous year's budget allocation. This allowed the funds to be released for redistribution for requests stated on the budget submissions. The Budget Review Subcommittee had the responsibility to review the submissions and to determine the method of distribution of the available funds, pending on the total amount of funding requests. The 
recurring portions of the funds must be given adequate increase upfront to pay all the bills for journal and database subscriptions, less the percent of serials cost increase to be covered through target savings from the annual serials rationalization exercise. Remaining funds were then redistributed for the provision of new resources in the electronic resources budgets and the print monographs budgets of the ten faculties based on criteria agreed upon and stated needs in the budget submissions.

\section{MZBB Allocation Outcomes}

\subsection{Monographs fund rationale}

In the sub-allocation of the print monograph portion of the budget among the ten faculties, all stated program needs including increased research activities were given highest priority. The flexibility to allocate limited funds to align exactly with curriculum and research activities and where most needed was one of the greatest benefits of the MZBB review. The MZBB review allowed for variable justifications in each of the disciplines. The provision of budget allocations, therefore, resulted in different support level for the each faculty as expressed in the budget submission (Table 1). The base figure for each faculty was additionally adjusted beyond the $95 \%$ using a ratio of base allocation to reflect the actual level of their current expenditures. This allowed unexpended funds to be released for redistribution towards higher priority needs. Therefore, faculties which did not spend all of their budgets ended up having a lower than the base allocation of 95\%. The budget allocations for Architecture and Dental faculties were both reduced as a result. These exceptional cases were of course carefully reviewed by the collection development head and subject librarians responsible to ensure that the information needs and collection goal level had indeed been met. The most common reason for under-spending was migration of resources to electronic. The adjustment reflecting current expenditures ensured that funds could be redirected from lower priority use to high priority use to improve effectiveness of expending the budget. The resulting allocations ranged from a reduction of $11 \%$ for Architecture 
to an increase of $25 \%$ for Law over the base budget.

Usage of collection was examined to help make informed decisions on what to buy more or less of. It is generally perceived that higher usage yields better return on funds invested. Increased use could indicate rising demand due to increase in student enrollment. Circulation statistics were examined in terms of percentage of expected use and the ratio of interlibrary loan to holdings. Subject areas in which the collection usage had been optimized (i.e. having better rate of expected use and higher ratio of interlibrary loan to holdings) were awarded additional requested funding.

Price change in monographs was considered case by case. There was no standard benchmark that could be relied on due to large discrepancies found among projections reported by major book vendors. Unless the projected increase was exceptionally high as in the case of Law, Medicine and Business materials, additional funds would not normally be allocated for this reason across the board, because materials pricing was already factored into the actual expenditure figures.

\subsection{Serials fund rationale}

In the MZBB review, it was made clear upfront that the total library materials budget increase was inadequate to cover full inflationary increase to permit retention of all existing printed serials subscriptions. The budget review committee decided that only partial inflationary increase would be granted based upon the level of duplicate print serials titles each faculty cancelled in the previous year, i.e., faculties which had made significant cancellation of print subscriptions were given larger increases than those which had made less cancellations, since significant saving could still be gained from further cancellation (Table 2). 
In recent years due to changes in learning technologies, HKUL has progressively shifted the collections budget from print to electronic resources to develop the electronic resources collections. This has been made possible through the annual serials review to retain only the journals deemed core and most essential which could not be substituted by article delivery. Since 2002, library-wide serials rationalization exercise has been conducted annually to scrutinize the decision to retain each subscription using several criteria: relevance, priority, demonstrated need, cost of journal subscription, number of use, cost per use, impact factor, and the availability of electronic versions including document delivery. This exercise was considered a part of the MZBB review and built into the budget allocation. Subject to faculty's endorsement to switch to electronic-only, the net savings realized from the switch to electronic remained in the faculty for purchasing new contents, while the subscription base portion was shifted to the Electronic Resources Fund to pay for the e-access. This has enabled the Libraries to re-prioritize needs due to technology and publishing trends and to re-allocate funds for digital resources without parallel budget increase to keep up with inflation.

New journals titles in support of program or research needs were not allocated additional funds, due to the format policy to subscribe the preferred e-only option. The funding strategy was to build new needs into requests for electronic resources fund, or to use savings realized from shifting to e-only in the case of print-only journals. The move to reliance upon electronic-only serials has allowed significant reduction of print serials expenditure. At the same time, it has helped to minimize the reduction in the monographs budget. In the serials budget allocation, faculties were made aware of the deficit of their projected serials account balance and the amount of target serials cut needed to balance their overall budget for books and serials. The overall serials base allocations were reduced across the board to allow funds shift to electronic.

\subsection{Electronic Resources fund rationale}


The MZBB budget review process for electronic resources began with a cost projection for the increased percentage of funds needed to pay for all e-resources recurring expenditures, taking into account the amount of switching of funds from print to electronic serials in the previous year. Outstanding recommendations pending funding as well as a prioritized list of new e-journals and databases to support teaching and research were built into the budget request. To prepare the MZBB submission, a meeting with the Shared Electronic Resources Fund Advisory Committee (SERFAC) was held to explain the rationale of the electronic resources budget projection and to seek members' advice, feedback, and support. Since SERFAC members understood that a larger percent spend on e-resources would mean less money for printed budgets, faculties generally supported further rationalization of print serial duplication to contain the overall budget. In convincing faculties to support further shift of funds from print to electronic, they were made aware that libraries are now accessing to contents much more abundantly through consortia access and joint consortium purchase, and that the growth in digital content has been quite tremendous considering the limited growth in the materials budget. For instance, electronic journal count has increased by $60 \%$ to 40,566 since 2004 , and the elimination of duplicate print subscriptions has resulted in lower serials unit cost. The cost benefit of accessing far more contents at a lower unit cost and the switching to e-only for a lower journal subscription cost were important factors to convince the faculties to give up more print-based resources in favor of a higher percent of electronic resources fund.

Digital publishing trends make it necessary to budget for a higher level of increase other than inflation. Increasingly, reference sources which used to be one-time purchases now require site license with recurring subscription costs. A number of high priority recommendations for purchase identified in response to program and research needs had remained outstanding and required new funds. Other justifications to increase the Shared Electronic Resources Fund included the exorbitant growth in use of electronic journals in particular, as well as the need to 
raise the collection level and acquisitions commitment in certain disciplines, such as Medicine and Business. When the percent of electronic resources expenditures as a percent of total Library Resources Fund has increased by as much as $122 \%$ in the last five years, while the total library materials budget only increased by $13 \%$ during the same period, it was important to justify the rationale behind the increase, especially to the teaching faculties.

\section{Impact of MZBB on the collections budget allocation}

The MZBB review required faculties to justify their future funding needs beyond the base budget by reviewing changes in curriculum/research, cost projections, organizational and environmental changes, such as, current teaching technology, increasing emphasis on electronic resources and diminishing use of printed journals. The needs were raised and submitted in the budget request to bid for extra funding. As a result, the Libraries was able to make budget allocations that align much closer to the future collection needs and objectives through rationalization and prioritization. The new budgets, although only partially re-justified, were not just “historic”, but based on actual new program needs that aligned with each faculty’s current academic development plan. Zero-based budgeting allows the base component to be set to an appropriate level that offers optimum fiscal flexibility. In this modified zero-based budget review, 95\% was deemed the suitable base level needed to achieve stability in supporting ongoing core programs. In times of budget reduction, the base could be reduced at a lower percent down to zero if warranted to constrain the budget (Linn, 2007). There is no expectation of perpetual funding as the base budget does not automatically roll over to the next fiscal year.

Perhaps the most successful learning outcome was the benefit to connect with campus faculty to enable them to understand more about the issues of developing hybrid collections with an emphasis on digital contents, and the publishing and price trends. Librarians also learned more about the specific program and interdisciplinary needs and expectations of information 
resources provision for teaching and research. As we continue to shift toward the provision for web-based access that relies on licensing agreements, with many in consortial model to optimize access, rather than purchasing of one-time traditional print based resources, the judgment and ability to align budgets with changing program needs and to balance the allocations for traditional and electronic resources become more critical. In general, faculties were more supportive in the overall budget allocation when the whole budget rationale was better understood as a result of their involvement in preparing the budget.

The MZBB process was absolutely manageable and the entire budget planning process including data preparation, budget submission and allocation was completed within four to six weeks. A full ZBB review would obviously take much more work to come up with pricing data of titles to justify every dollar from zero, but deemed unnecessary for materials budget allocation purpose because core resources must be provided. Overall, the MZBB review has achieved the aims of re-justifying and prioritizing collection needs, and at the same time permitting funds to be effectively channeled towards the highest priorities. Most importantly, the principles of ZBB provided the rationale for the entire allocation process which was more easily accepted and better understood by the university administration than a "home-grown” process.

\subsection{Conclusion}

ZBB is merited as a structured mechanism for providing fund justification using criteria agreed upon for management decisions to optimize budget allocations by prioritizing needs and objectives. The essence of ZBB is not to assume that previous years' activities or programs could be continually justified and given similar priority in future funding. In contrast with the earlier method of budget allocation before implementing MZBB, the ability to readjust the base allocation to release adequate funds for redistribution has facilitated fiscal flexibility to optimize the use of limited funds. A modified ZBB approach, such as the one described in this study, was 
considered a manageable and feasible option that could be repeated annually by libraries. In fact, we have heard from one faculty member that even in times of budget constraints, there is no compelling reason to justify the entire budget from zero due to an obvious need to support ongoing programs and the massive workload involved. Core collections are always needed to support academic programs. Hence, the MZBB was much more appropriate in allocation of library materials budget since past expenditure pattern does to a extent reflect actual information needs and the pricing of information resources.

The justification of funding based upon assessment of future information needs ensures that the Libraries build collections that align much closer to the new programmatic and strategic research needs of high priority areas. Involving faculty participation in the materials budget allocation process helps to raise awareness of the budget rationale, and would generally help the Libraries to gain more support in securing funding needs from central bodies. Finally, it was the professional judgment of librarians that was needed to balance the allocations for traditional and electronic resources, coupled with faculty input to reflect the latest development in academic direction to come up with an understandable and explicit library resources budget in the planning and decision process. The MZBB exercise has proved to be an effective approach in allocating collections budgets and a positive experience for all stakeholders. As of this writing, the Libraries has already successfully adopted MZBB in allocating its library materials budget for two years in a roll now. The Libraries will certainly continue to employ MZBB in future budgeting exercise, and will use the opportunity to work with faculty on the assessment review to better align budgets with program priorities. This model is recommended for libraries which are contemplating how to better align expenditures with real and emerging needs but feel they lack the fiscal flexibility to do so due to cutbacks or inadequate infusion of new funds. In fact, ZBB should be just as useful for reviewing other library budgets or other aspects of library service operation as most documented in the library literature (Foskett, 1991; Thompson 2005; Sargent 
1978; Crowe, 1982; Hayton 1980).

\section{References}

[1] Austin, A., and Cheek, L. M. (1979). Zero-Base Budgeting: A Decision Package Manual. New York: AMACOM.

[2] Clark, B., McCaslin, S., \& George, S. E. (2005). Floating Funds in a Shrinking Lake. The Serials Librarian, 48(3/4), 265-269.

[3] Zero Based Budgeting. (n.d.). Retrieved November 22, 2007, from CIPFA Web site: www.cipfa.org.uk/pt/download/zero_based_budgeting_bridfing.pdf

[4] Crowe, J. W. (1982). Zero-Base Budgeting for Libraries: a second look. College and research libraries, 43(1), 47-50.

[5] Foskett, D. J., \& Brindley, L. (1991). Zero-base budgeting: The Aston experience. Library Management, 12(4), 25-33.

[6] Hayton, E. (1980). Zero Base Budgeting in a University Library. Special Libraries, 71(3), 169-176.

[7] Linn, M. (2007). Budget systems used in allocating resources to libraries. The Bottom Line: Managing Library Finances, 20(1), 20-29.

[8] Peddie, C. (2003). Deep in the Pocket of Technology Creative Fiscal Management in Tight Times. In L. Lacy, W. S. Thieke, \& G. Farally-Semerad (Eds.), Proceedings of the 31st annual ACM SIGUCCS conference on User services 2003, San Antonio, TX, USA September 21-24, 2003 (pp. 48-50). New York: ACM.

[9] Promis, P. (1996). Developing a databased budget allocation strategy: The University of Arizona Library experience. Collection Building, 15(3), 5-9.

[10] Roberts, S. A. (2001). Trends and developments in financial management of collections in 
academic and research libraries. The Bottom Line: Managing Library Finances, 14(3), 152-163.

[11] Sargent, C. W. (1978). Zero-Base Budgeting and the Library. Bulletin of the Medical Library Association, 66(1), 31-35.

[12] Sudarsan, P. K. (2006). A resource allocation model for university libraries in India. The Bottom Line: Managing Library Finances, 19(3), 103-110.

Thompson, L. L., Toedter, L. J., \& D’Agostino, F. J. (2005). Zero-based print journal collection development in a community teaching hospital library: planning for the future. Journal of the Medical Library Association, 93(4), 427-430.

[13] Notes for Teaching and Research. (n.d.). Retrieved November 22, 2007, from The University of Hong Kong Web site:

https://www.hku.hk/apptunit/Notes-Teaching\&Research(49102).htm

[14] Weston, C. V. (2004). Breaking with the Past: Formula Allocation at Portland State University. The Serials Librarian, 45(4), 43-55. 